\title{
Use of the Acoustic Impulse-Response Technique for the Nondestructive Assessment of Manchego Cheese Texture
}

\author{
J. Benedito, ${ }^{1}$ T. Conde, G. Clemente, and A. Mulet \\ Department of Food Technology, Polytechnic University of Valencia, Camino de Vera, 46022 Valencia, Spain
}

\begin{abstract}
Manchego cheese pieces were hit with an impact probe and the acoustic response was recorded, analyzed, and used to assess the textural characteristics of the cheese pieces. The textural parameters measured by traditional instrumental methods increased during ripening, although the pattern of the increase was different for different batches. For the 2 acoustic impact probes used in this study, a change in the frequency spectrum took place as cheese matured, increasing higher frequencies and the energy content. Multiple linear regression (MLR) and partial least square regression (PLSR), considering the acoustical variables extracted from the spectrum, allowed for a good estimation of cheese texture. The textural characteristics of the cheese surface and in particular the maximum force in compression experiments $\left(\mathrm{R}^{2}>0.937\right.$ for MLR and $\mathrm{R}^{2}>0.852$ for PLSR) were accurately predicted by the acoustic method; however, the texture of the central layers of the cheese are poorly assessed $\left(R^{2}<0.720\right)$. The results obtained show the feasibility of using acoustic systems to assess Manchego cheese texture, aiding its classification.
\end{abstract}

Key words: Manchego cheese, texture, acoustic, impact

\section{INTRODUCTION}

Quality control in the food industry demands nondestructive automated techniques that can be placed online and used for the assessment of the entire production. Furthermore, these technologies should be reliable and inexpensive. At present there are several emerging nondestructive technologies applied to food products like the vibration rheometer, small displacement probes, visible, near, or mid-infrared spectroscopy, nuclear magnetic resonance, z-nose, electronic noses, computer vision, biosensors, and sonic and ultrasonic techniques.

Received February 14, 2006.

Accepted May 12, 2006.

${ }^{1}$ Corresponding author: jjbenedi@tal.upv.es
Elastic waves can be used to predict the structure, concentration, location, and physical state of different components in food products (McClements, 1997). Velocity, attenuation, and the frequency spectrum composition are the main parameters of interest when assessing food quality. Elastic waves have 2 main advantages over other nondestructive techniques: they can assess large widths of opaque materials, and they are relatively inexpensive. These techniques can be classified depending on the wave frequency; thus, ultrasonic $(>20 \mathrm{kHz})$ and sonic applications can be considered. The main disadvantage of these techniques is the attenuation of the elastic waves due to the scattering produced by occluded air in the samples. Attenuation increases as frequency increases, thus increasing its relevance for ultrasonic applications.

Ultrasonics has been used in the food industry for the quality assessment of fruits, meat and fish, drinks, oils, and also dairy products (McClements, 1997; Mulet et al., 2002; Benedito et al., 2004). Moreover, sonic waves can be used to characterize the physicochemical properties of food products. Sound can be introduced into the sample using a speaker and subsequently collected by a microphone. Using this set-up, the texture of nectarines, apricots, plums, and tomatoes has been evaluated by calculating velocity of the sonic waves (Muramatsu et al., 1996; Imran et al., 2004).

Alternatively, one destructive method is the use of the sound emitted by the food when it is compressed (sometimes broken) either in the mouth or with a texturometer to assess food properties. The information contained in the spectrum of the signal has been valuable, for example, to assess apple crispness (De Belie et al., 2000a), the texture of deep-fried foods (Toyoshima et al., 2004), or the crispness of snack products (Duizer and Campanella, 1998).

Finally, the impulse-response technique consists of application of an impact force on the surface of the sample and the measurement of the sample's response. The measurement of this response can be carried out with either an accelerometer or a microphone (acoustic impulse-response technique). The accelerometer has been applied mainly for apples (Schmulevich et al., 1996) and has the disadvantage of the need for proper 
attachment between the analyzed sample and the probe.

The acoustic impulse-response technique has also been used to assess the texture of tomatoes, apples, and pears (Schotte et al., 1999; De Belie et al., 2000a,b). This technique can be applied to detect eggshell cracks (Cho et al., 2000; De Ketelaere et al., 2000). Giangiacomo et al. (1989) used the acoustical impulse-response technique to detect internal cracks in Grana cheese. In these types of applications, the emitted sound is captured by a microphone, and the parameters obtained from the frequency spectrum analysis are related to the physicochemical properties of the food samples.

Texture is a key aspect in consumer's perception of cheese quality (Breuil and Meullenet, 2001). In addition, food texture has long been recognized as a multidimensional sensory quality, which manifests itself in many ways. As a result, numerous variables from instrumental tests must be considered to accurately characterize cheese texture (Breuil and Meullenet, 2001). Instrumental cheese texture has traditionally been evaluated by destructive sensory and instrumental measurements, with texture profile analysis, uniaxial compression and puncture tests being the most frequently used instrumental techniques. New nondestructive tests are emerging for cheese texture evaluation. Some of the examples reported in the literature are vibrating rheometers, small displacement probes, infrared and fluorescence spectroscopy, and ultrasonics (Benedito et al., 2000a, 2006; Kulmyrzaev et al., 2005).

Manchego cheese is the most popular ewe's milk cheese produced and consumed in Spain. It is a cured, semihard, enzymatically coagulated, uncooked, pressed, high-fat cheese. As required by the Regulatory Board of the Manchego Cheese Appelation of Origin, the minimum ripening time of cheeses before marketing is $60 \mathrm{~d}$. As with other types of hard cheeses, Manchego cheese matures unpacked in temperature- and relative humidity-controlled chambers. During this stage, water loss and proteolysis result in an increase in the textural properties that can be used to assess the degree of cheese maturity (Benedito et al., 2006). Sometimes it is difficult to determine the state of maturity of a batch given the lack of uniformity in the curing chambers and differences in milk and manufacturing conditions. Circumstances such as those lead to heterogeneous batches that are unappealing to retailers and consumers.

Ultrasonics has been used to assess the texture of Mahon and Cheddar cheeses (Benedito et al., 2000a,b). However, Benedito et al. (2006) found that ultrasonic waves were highly attenuated by Manchego cheese due to porosity, and only 2 -cm cubes could be correctly eval- uated. Lower frequency elastic waves need be used to assess whole pieces of cheese.

The objective of this study was to assess the suitability of using the acoustic impulse-response technique to evaluate Manchego cheese texture and maturity. The texture of the cheese surface and the internal texture were determined by traditional textural analysis (uniaxial compression and puncture) and multiple linear regression (MLR). Partial least square regression (PLSR) models were then developed to predict cheese texture from acoustic measurements.

\section{MATERIALS AND METHODS}

\section{Raw Material}

Three batches of Certified Origin Manchego cheese pieces were used in this study. Cheeses ranged from 36 to $156 \mathrm{~d}$ of maturity for batch 1 (18 pieces), from 140 to $218 \mathrm{~d}$ for batch 2 (18 pieces), and from 219 to $336 \mathrm{~d}$ for batch 3 ( 28 pieces). All the pieces were manufactured by the same company located in Albacete, Spain, following the cheese-maker's commercial manufacturing procedures, although the pieces were made from different milk curd batches and were ripened under different conditions. The pieces were cylindrically shaped, measuring $10 \pm 1 \mathrm{~cm}$ in height and $19 \pm 0.5 \mathrm{~cm}$ in diameter. They all weighed $2.9 \pm 0.4 \mathrm{~kg}$. The pieces of all the batches were transported in refrigerated trucks from the company to the laboratory. The dimensions and weight were determined prior to instrumental analysis.

\section{Moisture Content}

The moisture content was determined for all the cheese pieces by taking the sample from the center of the cheese. The methodology involved weighing each sample before and after drying in an oven at $100^{\circ} \mathrm{C}$ for $24 \mathrm{~h}$ (AOAC, 1984).

\section{Texture}

The textural analysis of the cheese pieces was carried out using a Universal Testing Machine (TA.XT 2i, 25 $\mathrm{kg}$, Stable Micro Systems, Surrey, UK) placed in a temperature controlled chamber at $12 \pm 0.5^{\circ} \mathrm{C}$. The samples were previously stored at this temperature to ensure a uniform temperature distribution. Measurements were performed on the cheese surface and on the inside of the wheel.

Surface Analysis. The surface texture assessment was carried out on the whole cheese pieces using 2 different probes. A spherical $(2.5 \mathrm{~cm}$ diameter) and a semispherical (6 $\mathrm{cm}$ diameter) probe were fitted to the 


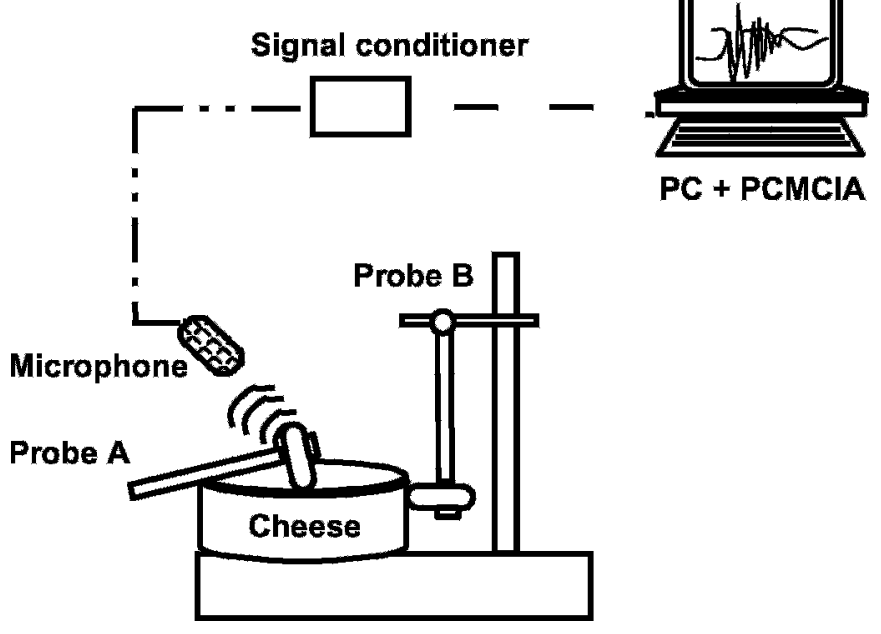

Figure 1. Set-up used in the acoustic measurements.

load cell; and a crosshead speed of $1 \mathrm{~mm} / \mathrm{s}$ and a displacement distance of $4 \mathrm{~mm}$ were used. For these tests, the maximum force (MF), the distance to achieve the maximum force (DMF), the downstroke compression work, the upstroke work, as well as the initial compression slope were determined (Benedito et al., 2006). Ten measurements ( 5 on each flat face of the cylindricalshaped cheese piece) were carried out and averaged for each probe.

Internal Measurements. To determine the internal texture of the cheese, samples were obtained from the center $( \pm 3 \mathrm{~cm}$ from the horizontal central axis) of the cheese pieces where the uniformity is higher. A compression test was performed on 10 cheese cubes of 2$\mathrm{cm}$ dimension. The cubes were compressed $10 \mathrm{~mm}(50 \%)$ at a crosshead speed of $0.2 \mathrm{~mm} / \mathrm{s}$. The deformability modulus, hardness, the distance to achieve the maximum force, and the compression work were computed. Further, 10 puncture measurements were performed on cheese slices of $20-\mathrm{mm}$ thickness. To this end, a cylindrical probe measuring $6 \mathrm{~mm}$ in diameter was fitted to the cell (crosshead speed $0.2 \mathrm{~mm} / \mathrm{s}, 2-\mathrm{mm}$ compression). Maximum in puncture, puncture work, the distance at the maximum force, and the slope in puncture were calculated (Benedito et al., 2000a).

\section{Acoustic Impulse-Response Technique}

To carry out the nondestructive cheese assessment, the acoustic set-up (Figure 1) consisted of a stainless steel impact probe and a microphone (sensitivity: 46.84 $\mathrm{mV} / \mathrm{Pa}$; frequency response: $\pm 2 \mathrm{~dB} 3.15 \mathrm{~Hz}$ to $20 \mathrm{kHz}$; $\pm 1 \mathrm{~dB} 12.5 \mathrm{~Hz}$ to $10 \mathrm{kHz}$; GRASS, Sound and Vibration, 1", $40 \mathrm{AF}$, Denmark) fitted to a preamplifier (GRASS,
Sound \& Vibration, $1 / 2$ ", 26AF, Denmark). The preamplifier was linked to a signal conditioner (OPUS, 01dBStell, MUI Technologies Groups, Paris, France) that powered the system and amplified $(20 \mathrm{~dB})$ and filtered (10-Hz high pass filter) the signal. The signal was digitized in a PCMCIA card (National Instruments, 20 Msamples/s, NI5102, Austin, TX).

Modal analysis allows gathering of very valuable information such as optimum location of excitation and sensing parts and modes of vibration when carrying out impact-response experiments (Lu and Abbott, 1996; De Belie et al., 2000a). However, in our application the lack of homogeneity within the cheese (texture profile), the irregular crust shape provided by the molds in which the pieces had been pressed, and the boundary constraint arising from the fact that the cheese pieces were placed on a flat surface for the experiments (Figure 1), have limited the use of the modal analysis.

Two types of experiments were conducted to extract information from the different modes of vibration and therefore extract the maximum information about the cheese mechanical properties. A hand-operated stainless steel probe (probe A, $257 \mathrm{~g}, 2.6 \mathrm{~cm}^{2}$ flat contact surface, velocity at impact: $2.71 \mathrm{~m} / \mathrm{s}$; probes were manufactured in our laboratory) was used to strike on the flat surface of the cylindrical pieces ( 5 strikes on each side of the cheese). In these experiments, the probe operator was always the same so as to maintain the impact conditions constant. On the other hand, a 145$\mathrm{g}$ stainless steel probe (probe B) attached to a rotating arm $(29.3 \mathrm{~cm}$ in length, velocity at impact: $2.10 \mathrm{~m} / \mathrm{s})$ was released from its resting point following a circular trajectory $\left(50^{\circ}\right)$ before it struck the lateral (round) side of the wheel. Different points of the lateral surface were struck 10 times with this probe. The aim was to collect the sound emitted by the vibration of the samples when the pieces were hit. The position of the sensor was determined in previous experiments according to the following rules: Obtain a recordable signal and maximize the differences in the spectrum from soft to matured pieces. The microphone for both probes was placed $2 \mathrm{~cm}$ above the flat cheese surface and $5 \mathrm{~cm}$ from the center of the pieces. For each strike, the signal was digitized and the fast-Fourier transform (FFT) calculated. The spectrum was divided in different sections to find frequency ranges containing peaks in amplitude and frequency distribution that could be clearly identified and compared for cheeses with different ripening times. For probe A the spectrum was divided into 3 sections: from 19 to $54 \mathrm{~Hz}$ (section 1), from 54 to $134 \mathrm{~Hz}$ (section 2), and from 134 to $1,000 \mathrm{~Hz}$ (section 3). The central frequency ( $\mathbf{C F}$, Equation 1) was calculated for the whole spectrum (all 3 sections) and for each section $\left(\mathrm{CF}_{1}, \mathrm{CF}_{2}\right.$, $\mathrm{CF}_{3}$ ). The moments of order $0\left[\mathrm{M}_{0}\right.$ (Equation 2)], order 
$1\left[\mathrm{M}_{1}\right.$ (Equation 3)], and variance (Var, Equation 4) for the whole spectrum, as well as $\mathrm{M}_{0}$ for each section $\left(\mathrm{M}_{01}\right.$, $\mathrm{M}_{02}, \mathrm{M}_{03}$ ) were calculated.

The spectrum for probe $\mathrm{B}$ was divided into 2 sections: from 93 to $815 \mathrm{~Hz}$ (section 1) and from 815 to 2,000 $\mathrm{Hz}$ (section 2). The $\mathrm{CF}$ was calculated for the whole spectrum and for each section $\left(\mathrm{CF}_{1}, \mathrm{CF}_{2}\right)$. The moments of order 0 and 1 for sections 1 and $2\left(\mathrm{M}_{0}, \mathrm{M}_{01}, \mathrm{M}_{02}, \mathrm{M}_{1}\right.$, $\mathrm{M}_{11}, \mathrm{M}_{12}$ ) and Var were also calculated:

$$
\begin{gathered}
C F=\frac{M_{1}}{M_{0}} \\
M_{0}=\sum_{f 1}^{f 2} X(f) \times \Delta f \\
M_{1}=\sum_{f 1}^{f 2} X(f) \times f \times \Delta f \\
\operatorname{Var}=\frac{\sum_{f 1}^{f 2}(f-C f) \times X(f)}{\sum_{f 1}^{f 2} X(f)}
\end{gathered}
$$

where $\mathrm{f}$ is the frequency and $\mathrm{X}(\mathrm{f})$ is the amplitude of the FFT.

The calculation of the FFT and the different parameters from the spectrum was carried out using macros programmed in Visual Basic for Excel.

\section{Statistical Treatment}

Simple and multiple regression analyses were performed on the data using Statgraphics Plus 5.1 (Manugistics, Rockville, MD). The software used calculated both types of regression using least squares to estimate the regression model. To fit the multiple regression and to determine the number of variables included in the models relating the acoustic and textural measurements, the backward selection method (backward stepwise selection, F-to-remove $=4$, Statgraphics Plus 5.1) was used.

The principal component analysis (PCA, SIMCA-P 10) was used to analyze the grouping characteristics of the data set and to reduce the information from the large number of variables considered into a smaller set.

Relationships between acoustic measurements and textural parameters and moisture were also established by PLSR (SIMCA-P10). The cross-validation method was used on centered data (Poveda et al., 2004). Each variable was weighted by its respective standard deviation so that each variable was given the same probability to influence the predictive model. For this method, the number of components in the model is chosen according to the goodness of prediction parameter $\mathrm{Q}^{2}$ (Equation 5).

$$
Q^{2}=1-\frac{P R E S S}{R S S}
$$

where PRESS in the cross-validation method is the sum of the squared differences between observed and predicted values for the data kept out of the model fitting after all the data has been kept out once and only once; and RSS is the residual sum of squares of the previous component.

In the PLSR all the variables (textural parameters and moisture and acoustical parameters) were included in a single model, this characteristic together with the cross validation method being the most interesting features of this regression technique.

\section{RESULTS AND DISCUSSION}

\section{Changes of Cheese Texture During Ripening}

During Manchego cheese ripening, water loss and proteolysis result in a change of the textural properties, which can thus be used to evaluate the degree of cheese maturity (Benedito et al., 2006). In this study, all the internal and external textural measurements except DMF (for the semispherical probe and uniaxial compression) increased during ripening (Table 1).

Figure 2 shows the increase of MF (spherical probe) during cheese ripening. As illustrated, batch 1 follows a different behavior pattern than batches 2 and 3 (a similar pattern is found for the other surface textural measurements). The linear correlation coefficients considering only batches that showed similar ripening behavior (batches 2 and 3) significantly increased (Table 1). The best linear correlation coefficient for the change of the textural parameters over time for the spherical probe corresponds to MF ( $\mathrm{r}=0.790$ and 0.904 for all batches and batches 2 and 3, respectively). For the semispherical probe, $\mathrm{MF}(\mathrm{r}=0.814$ and 0.920$)$ is the textural parameter with the highest scores. This heterogeneity in the textural behaviors during ripening can be attributed to differences in raw material and manufacturing conditions.

As mentioned before, product uniformity in a commercial batch is a key aspect that must be controlled for quality purposes. In this regard and for this study, cheeses with more than 100 days' difference in maturity (batches 1 and 2) showed similar externally measured textural characteristics (Figure 2).

The same distinctive behavior for different batches is also observed for the internal (center) cheese texture 
Table 1. Linear correlation coefficients between textural parameters and maturing time ${ }^{1}$

\begin{tabular}{|c|c|c|c|}
\hline & & All batches & $\begin{array}{l}\text { Batches } 2 \\
\text { and } 3\end{array}$ \\
\hline Surface spherical probe ${ }^{2}$ & $\begin{array}{l}\text { MF (N) } \\
\text { WSD }(\mathrm{N} \cdot \mathrm{mm}) \\
\text { DMF }(\mathrm{mm}) \\
\text { WSU }(\mathrm{N} \cdot \mathrm{mm}) \\
\text { SS }(\mathrm{N} / \mathrm{mm})\end{array}$ & $\begin{array}{l}0.790 \\
0.769 \\
0.101^{* *} \\
0.767 \\
0.742\end{array}$ & $\begin{array}{l}0.904 \\
0.881 \\
0.020 * * \\
0.883 \\
0.894\end{array}$ \\
\hline Surface semispherical probe & $\begin{array}{l}\text { MF }(\mathrm{N}) \\
\text { WSD }(\mathrm{N} \cdot \mathrm{mm}) \\
\text { DMF }(\mathrm{mm}) \\
\text { WSU }(\mathrm{N} \cdot \mathrm{mm}) \\
\text { SS }(\mathrm{N} / \mathrm{mm})\end{array}$ & $\begin{array}{c}0.814 \\
0.813 \\
-0.067^{* *} \\
0.801 \\
0.790\end{array}$ & $\begin{array}{l}0.920 \\
0.912 \\
0.348^{*} \\
0.910 \\
0.914\end{array}$ \\
\hline Puncture test $^{3}$ & $\begin{array}{l}\mathrm{MP}(\mathrm{N}) \\
\mathrm{PW}(\mathrm{N} \cdot \mathrm{mm}) \\
\mathrm{DMFP}(\mathrm{mm}) \\
\mathrm{SP}(\mathrm{N} / \mathrm{mm})\end{array}$ & $\begin{array}{l}0.471 \\
0.357 \\
0.585 \\
0.562\end{array}$ & $\begin{array}{l}0.540 \\
0.325^{*} \\
0.395 \\
0.460\end{array}$ \\
\hline \multirow[t]{2}{*}{ Uniaxial compression $^{4}$} & $\begin{array}{l}\mathrm{H}(\mathrm{N}) \\
\mathrm{DMFC}(\mathrm{mm}) \\
\mathrm{CW}(\mathrm{N} \cdot \mathrm{mm}) \\
\mathrm{DM}(\mathrm{kPa})\end{array}$ & $\begin{array}{r}0.619 \\
-0.362 \\
0.684 \\
0.742\end{array}$ & $\begin{array}{l}0.561 \\
-0.207 * * \\
0.607 \\
0.832\end{array}$ \\
\hline & Moisture (wt \%) & -0.743 & -0.596 \\
\hline
\end{tabular}

${ }^{1}$ Values with no asterisk indicate that the relationships are statistically significant $(P<0.01)$.

${ }^{2} \mathrm{MF}$ = Maximum force; WSD = downstroke compression work; DMF = distance to maximum force; WSU = upstroke work; SS = initial compression slope.

${ }^{3} \mathrm{MP}=$ Maximum in puncture; $\mathrm{PW}=$ puncture work; DMFP = distance maximum force to puncture; $\mathrm{SP}=$ slope in puncture.

${ }^{4} \mathrm{H}=$ Hardness $; \mathrm{DMFC}=$ distance to maximum force to compress; $\mathrm{CW}=$ compression work; $\mathrm{DM}=$ deformability modulus.

$* P>0.01 ; * * P>0.05$.

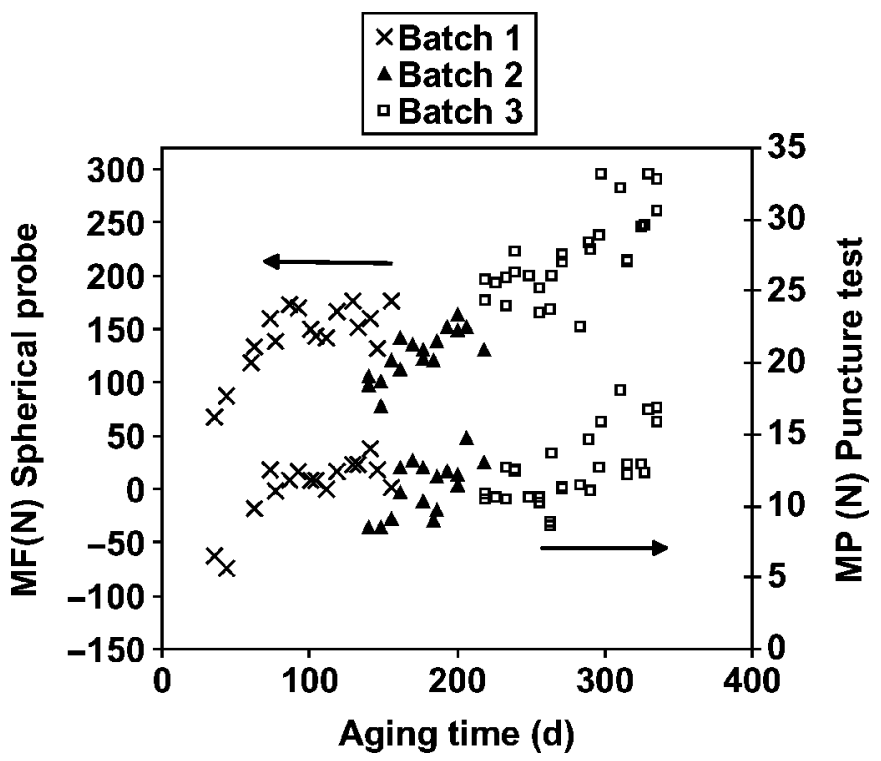

Figure 2. Change of surface and internal textural characteristics of Manchego cheese during ripening. $\mathrm{MF}$ = maximum force; $\mathrm{MP}=$ maximum in puncture. Maturity of pieces: batch $1=36$ to $156 \mathrm{~d}$; batch $2=140$ to $218 \mathrm{~d}$; and batch $3=219$ to $336 \mathrm{~d}$.
(Figure 2) although in this case the variability is higher, which is also observed in the lower correlation coefficients shown in Table 1 . In the case of the puncture test and uniaxial compression, due to the high variability, the reduction in the number of observations counteracts the effect of removing batch 1 in the regression (Table 1) and therefore an increase in the coefficients is not observed. The distance at the maximum force $(\mathrm{r}=$ $0.585)$ and the maximum in puncture $(\mathrm{r}=0.540)$ had the best correlation coefficients when all batches and only batches 2 and 3 are considered, respectively. For the compression tests, the DM is the parameter that is best related to the ripening time. The low correlation coefficients show that there is high variability in the analyzed pieces of cheese; revealing that the maturing time does not properly describe the changes that take place in the pieces, namely cheese texture.

Due to the large number of variables and observations, a PCA analysis was carried out on all the textural data and moisture so as to gain an understanding of the relationship among the variables; i.e., which variables contribute similar information and which contribute unique information about the observations. Three principal components (PC) were obtained, explaining $80.9 \%$ 
Table 2. Loading matrix for the principal component (PC) analysis of the textural variables

\begin{tabular}{|c|c|c|c|c|}
\hline & & $\begin{array}{l}\text { PC1 } \\
(62.7 \%)^{1}\end{array}$ & $\begin{array}{l}\text { PC2 } \\
(11 \%)^{1}\end{array}$ & $\begin{array}{l}\text { PC3 } \\
(7.2 \%)^{1}\end{array}$ \\
\hline Surface spherical probe ${ }^{2}$ & $\begin{array}{l}\text { MF (N) } \\
\text { WSD }(\mathrm{N} \cdot \mathrm{mm}) \\
\text { DMF }(\mathrm{mm}) \\
\text { WSU }(\mathrm{N} \cdot \mathrm{mm}) \\
\mathrm{SS}(\mathrm{N} / \mathrm{mm})\end{array}$ & $\begin{array}{l}-\mathbf{0 . 9 6 1} \\
-\mathbf{0 . 9 5 5} \\
-0.141 \\
-\mathbf{0 . 9 5 0} \\
-\mathbf{0 . 9 4 1}\end{array}$ & $\begin{array}{r}-0.185 \\
-0.169 \\
\mathbf{0 . 7 2 4} \\
-0.217 \\
-0.204\end{array}$ & $\begin{array}{l}0.157 \\
0.194 \\
\mathbf{0 . 5 8 8} \\
0.165 \\
0.206\end{array}$ \\
\hline Surface semispherical probe & $\begin{array}{l}\text { MF }(\mathrm{N}) \\
\text { WSD }(\mathrm{N} \cdot \mathrm{mm}) \\
\text { DMF }(\mathrm{mm}) \\
\text { WSU }(\mathrm{N} \cdot \mathrm{mm}) \\
\text { SS }(\mathrm{N} / \mathrm{mm})\end{array}$ & $\begin{array}{r}-\mathbf{0 . 9 5 8} \\
-\mathbf{0 . 9 5 1} \\
0.125 \\
-0.869 \\
-\mathbf{0 . 9 3 6}\end{array}$ & $\begin{array}{r}-0.161 \\
-0.166 \\
\mathbf{0 . 8 3 1} \\
-0.164 \\
-0.195\end{array}$ & $\begin{array}{l}0.170 \\
0.189 \\
0.343 \\
0.128 \\
0.216\end{array}$ \\
\hline Puncture test ${ }^{3}$ & $\begin{array}{l}\mathrm{MP}(\mathrm{N}) \\
\mathrm{PW}(\mathrm{N} \cdot \mathrm{mm}) \\
\mathrm{DMFP}(\mathrm{mm}) \\
\mathrm{SP}(\mathrm{N} / \mathrm{mm})\end{array}$ & $\begin{array}{l}-0.840 \\
-0.682 \\
-0.509 \\
-0.776\end{array}$ & $\begin{array}{r}0.292 \\
0.404 \\
-0.098 \\
0.224\end{array}$ & $\begin{array}{l}-0.211 \\
-0.362 \\
-0.319 \\
-\mathbf{0 . 3 9 6}\end{array}$ \\
\hline \multirow[t]{2}{*}{ Uniaxial compression ${ }^{4}$} & $\begin{array}{l}\mathrm{H}(\mathrm{N}) \\
\mathrm{DMFC}(\mathrm{mm}) \\
\mathrm{CW}(\mathrm{N} \cdot \mathrm{mm}) \\
\mathrm{DM}(\mathrm{kPa})\end{array}$ & $\begin{array}{r}-0.773 \\
0.399 \\
-0.834 \\
-\mathbf{0 . 9 0 8}\end{array}$ & $\begin{array}{r}0.349 \\
-0.257 \\
0.278 \\
0.017\end{array}$ & $\begin{array}{r}-0.073 \\
\mathbf{0 . 3 9 8} \\
-0.119 \\
-0.085\end{array}$ \\
\hline & Moisture (wt \%) & 0.707 & -0.159 & 0.138 \\
\hline
\end{tabular}

${ }^{1}$ Percentage of explained variance by each $\mathrm{PC}$; values in bold indicate the variables that are highly correlated to each PC.

${ }^{2} \mathrm{MF}$ = Maximum force; WSD = downstroke compression work; DMF = distance to maximum force; WSU = upstroke work; SS = initial compression slope.

${ }^{3} \mathrm{MP}=$ Maximum in puncture; $\mathrm{PW}=$ puncture work; $\mathrm{DMFP}=$ distance maximum force to puncture; $\mathrm{SP}=$ slope in puncture.

${ }^{4} \mathrm{H}=$ Hardness ; DMFC = distance to maximum force to compress $; \mathrm{CW}=$ compression work; $\mathrm{DM}=$ deformability modulus.

of the total variance. Table 2 shows the component loading matrix, which indicates the contribution of the variables to each $\mathrm{PC}$ (PC1, PC2, and PC3). In bold letters are indicated the variables that are highly correlated to each PC.

Figure 3 shows the loading plot of the textural data set for PC1 vs. PC2. It can be observed that for all the analyses, the textural parameters (except the distances at the maximum force) are clustered to the left of the negative PC1 axis. This grouping indicates that this component explains the overall increase in texture during ripening. On the other side of the plot, the moisture follows an opposite tendency to that of texture during cheese ripening (Table 1), because the decrease in moisture results in an increase of cheese firmness (Benedito et al., 2000c). The poor relationship between the distance at the maximum force and curing time is also depicted in Figure 3 because this parameter is isolated from the other textural parameters and is closer to the origin. Furthermore, PC2 allows distinction between texture measured at the cheese surface (negative side) and internal parameters (positive side). The loads of the surface parameters are much closer to each other than the internal textural properties. The different position on the PC2 axis shows that the internal and

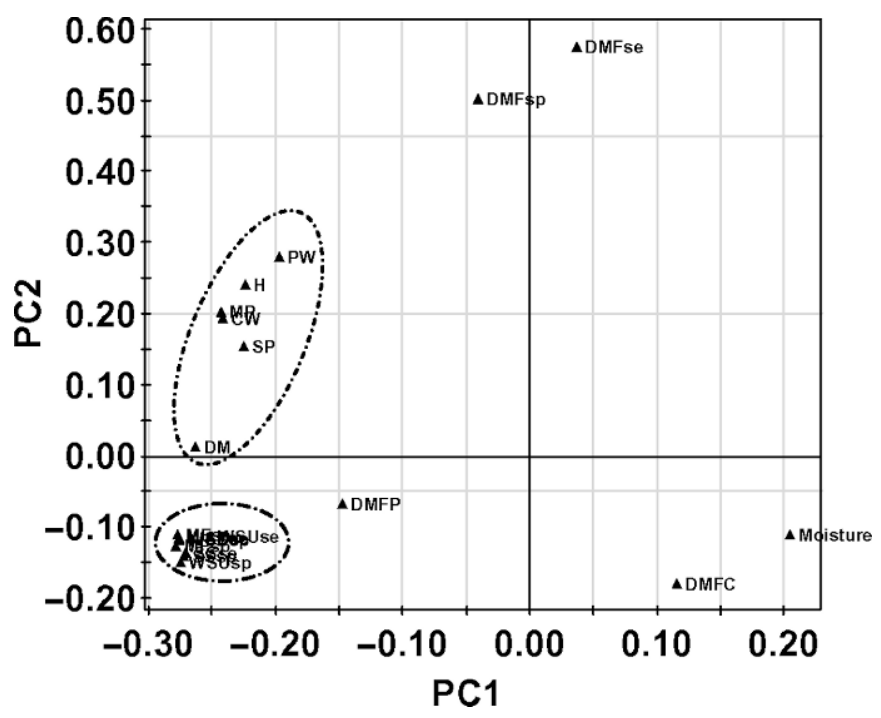

Figure 3. Principal component (PC) analysis loading plot of the surface and internal textural parameters of Manchego cheese. $\mathrm{MF}=$ Maximum force; WSD = downstroke compression work; DMF = distance to maximum force; WSU = upstroke work; $\mathrm{SS}=$ initial compression slope $; \mathrm{MP}=$ maximum in puncture $\mathrm{PW}=$ puncture work ; DMFP = distance maximum force to puncture; $\mathrm{SP}=$ slope in puncture; $\mathrm{H}$ $=$ hardness; $\mathrm{DMFC}=$ distance to maximum force to compress; $\mathrm{CW}=$ compression work; DM = deformability modulus; subscript se $=$ semispherical probe; $\mathrm{sp}=$ sperical probe. 
external textures change in different ways during ripening. In fact, when relating the external to the internal textural parameters, the linear correlation coefficients were always lower than 0.7 , except for the DM. In the case of DM, the linear correlation coefficients between this parameter and the external textural ones (except for the distances at the maximum force) ranged from 0.794 to 0.841 . This singularity of DM is also shown in Figure 3 because DM is located much closer to the negative values of $\mathrm{PC} 2$ than any other internal parameter. The plot of PC1 vs. PC3 is similar to Figure 3, but PC3 not only distinguishes between external and internal textural parameters, but it also shows different loadings for the puncture and compression analysis, the latter parameters being closer to the origin of PC3.

Benedito et al. (2006) described a good linear relationship between the internal and external textural parameters in a batch of cheeses matured from 29 to $296 \mathrm{~d}$. However, in the current study, the poorer relationships found between internal and surface texture show that the differences in the chamber's maturing conditions can result in heterogeneity of the texture distribution and thus in different patterns for the internal-surface texture relationships.

\section{Acoustic Impulse-Response Measurements}

Figure 4 show the spectra of 3 cheeses with different maturities for probes A and B. A preliminary observation indicates that the main differences in the spectra for cheeses of different maturations in the case of probe A are located in section 3. In this section, the amount of energy is higher for pieces with longer ripening times (Figure 4a). In the case of probe B, the spectrum in section 1 moves toward higher frequencies for longer ripening times. As with probe A, the energy of the higher frequency content section (section 2) also increases for longer periods of maturity (Figure 4b).

To characterize the acoustic response of the samples to the impact, the parameters described previously above were calculated. Figure 5 shows the changes of the $\mathrm{CF}$ for probes A and B. As previously observed in Figures $4 \mathrm{a}$ and $\mathrm{b}$, the increase in maturity leads to an increase of $\mathrm{CF}$ due to the higher frequency content of the spectrum. Furthermore, and as with the textural measurements (Figure 2), batches 2 and 3 had a similar behavior whereas the increase in the $\mathrm{CF}$ of batch 1 was steeper (Figure 5).

All the acoustic parameters increased for longer ripening times, the correlation coefficients between the acoustic parameters and time being low (Table 3). For probe $\mathrm{A}$, the best relationship was for $\mathrm{M}_{1}(\mathrm{r}=0.828)$ and $\mathrm{CF}_{1}$ for probe $\mathrm{B}(\mathrm{r}=0.762)$.
Four components were obtained in the PCA, explaining $88.6 \%$ of the total variance. Table 4 shows the component loading matrix, which indicates the contribution of the variables to each PC. In bold letters are indicated the variables that are highly correlated to each PC. The PCA (Figure 6) revealed that a group of variables with similar loads is found to the right of the PC1 axis. The variables located closer to the x-axis origin $\left(\mathrm{M}_{01}, \mathrm{CF}_{2}\right.$ for probe $\mathrm{A}$ and $\mathrm{M}_{01}, \mathrm{CF}_{2}$ and Var for probe B) corresponded to parameters that had the worst correlation coefficients $(r<0.36$, Table 3$)$.

The increase in the textural parameters seems to involve changes in the acoustical parameters measured by the impulse-response technique. Namely, an increase in the acoustic frequency as well as a higher energy content is observed for cheese pieces with longer ripening times and thus higher values for the textural properties.

Most of the studies that have used this technology to assess changes in texture related to ripening have been focused on fruits and vegetables. In these studies the selected parameter was resonant frequency (RF, selected peak frequency in the spectrum). An exponential decrease of stiffness ( stiffness $=\mathrm{RF}^{2} \cdot \mathrm{mass}^{2 / 3}$ ) was found for tomatoes of increasing ripeness (Schotte et al., 1999). Contrary to tomatoes, the cheese textural parameters increased linearly during storage, although with a high variability (Table 1). Nonetheless, a change of the linear tendency is expected for maturities beyond the maximum aging time considered in this study.

De Belie et al. (2000b) found a decrease of resonant frequency when monitoring firmness changes in Conference and Doynné pears on the tree, whereas Lu and Abbott (1996) found a similar influence of fruit maturity in the resonant frequency for apples. For the spectra obtained in our cheese samples, the CF (Equation 1), which is calculated from the whole spectra, lead to a better description of the changes found during cheese ripening than a particular peak.

\section{Relationship Between Texture and Impulse- Acoustic Measurements}

To assess cheese maturity and texture using acoustic measurements, relationships between acoustic parameters and textural properties were sought. Table 5 shows the linear correlation coefficients. As observed, the best predictor of the textural parameters for both probes is the $\mathrm{CF}$ of the spectrum.

When analyzing the results for probe $\mathrm{A}$, the best correlation coefficients corresponded to the $\mathrm{CF}$ and the $\mathrm{MF}$ for the spherical and semispherical probes $(r=0.841$ and 0.830 , respectively). Further, good predictions of $\mathrm{DM}$ and compression work can be made from the $\mathrm{CF}$ 

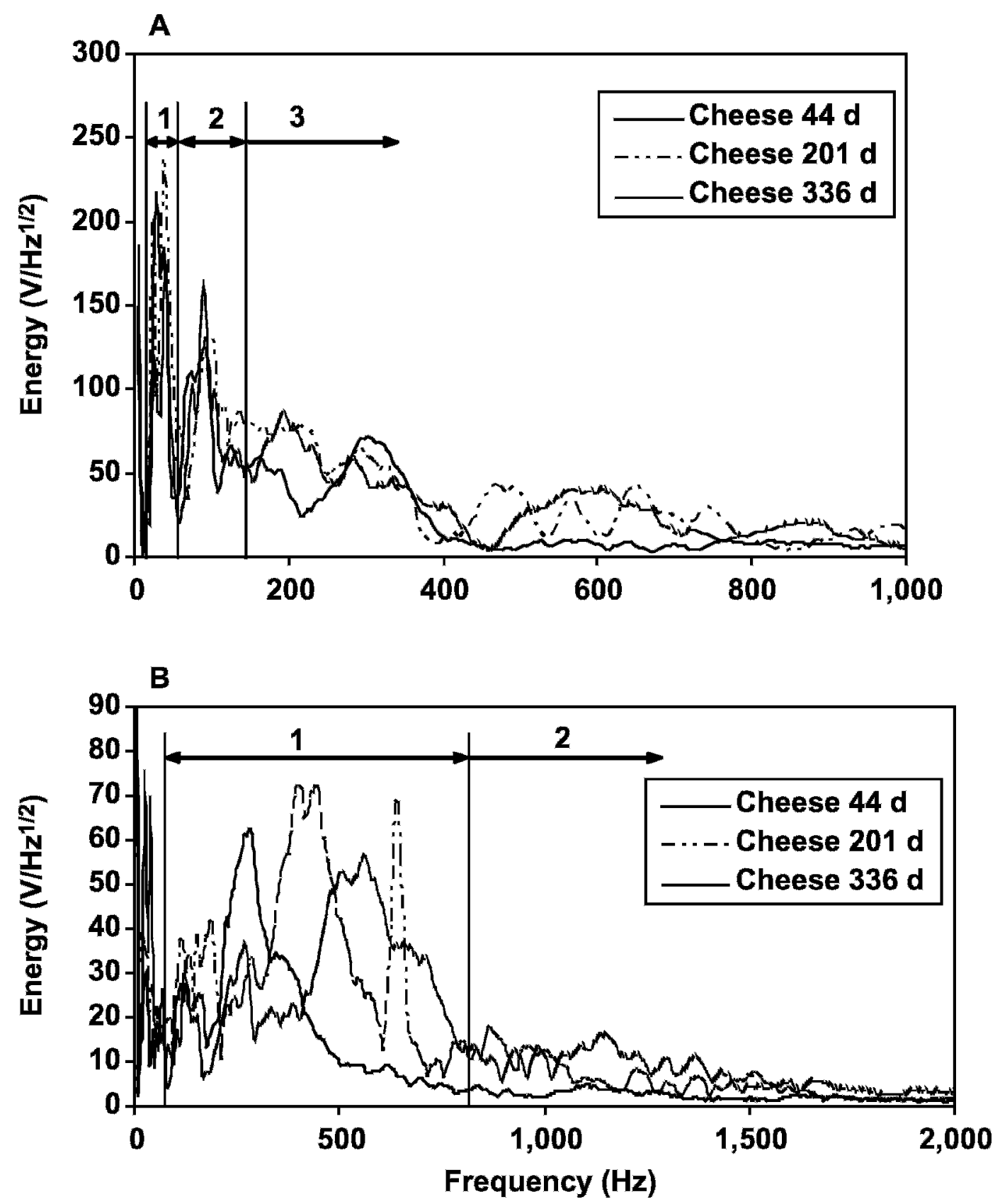

Figure 4. Acoustic spectra of cheeses with different ripening times for impact probes A (top) and B (bottom). Probe A: segment $1=19$ to $54 \mathrm{~Hz}$, segment $2=54$ to $134 \mathrm{~Hz}$, segment $3=134$ to $1,000 \mathrm{~Hz}$. Probe B: segment $1=93$ to $815 \mathrm{~Hz}$, segment $2=815$ to $2,000 \mathrm{~Hz}$.

(Table 5). This impact probe can also facilitate information regarding the values of the textural characteristics of cheese from the energy of the spectrum $\left(\mathrm{M}_{1}\right.$ and $\left.\mathrm{M}_{03}\right)$. These values increase, as does the texture of the cheese (Table 5). Comparing the information provided by each section of the spectrum, it seems that section $3\left(\mathrm{CF}_{3}\right.$ and $\mathrm{M}_{03}$ ) contains most of the changes in the vibration behavior that take place in the cheese pieces during ripening due to the changes in texture. The correlation coefficients between the acoustical measurements and the internal texture are lower than those for the external ones. The best predictor of the internal parameters is the $\mathrm{CF}$ and, in particular, the best correlation coefficient corresponds to the relationship between $\mathrm{CF}$ and $\mathrm{DM}(\mathrm{r}=0.704)$. This can be attributed to the fact that this parameter was more closely related to the external textural measurements than to the other internal variables (Figure 3). 


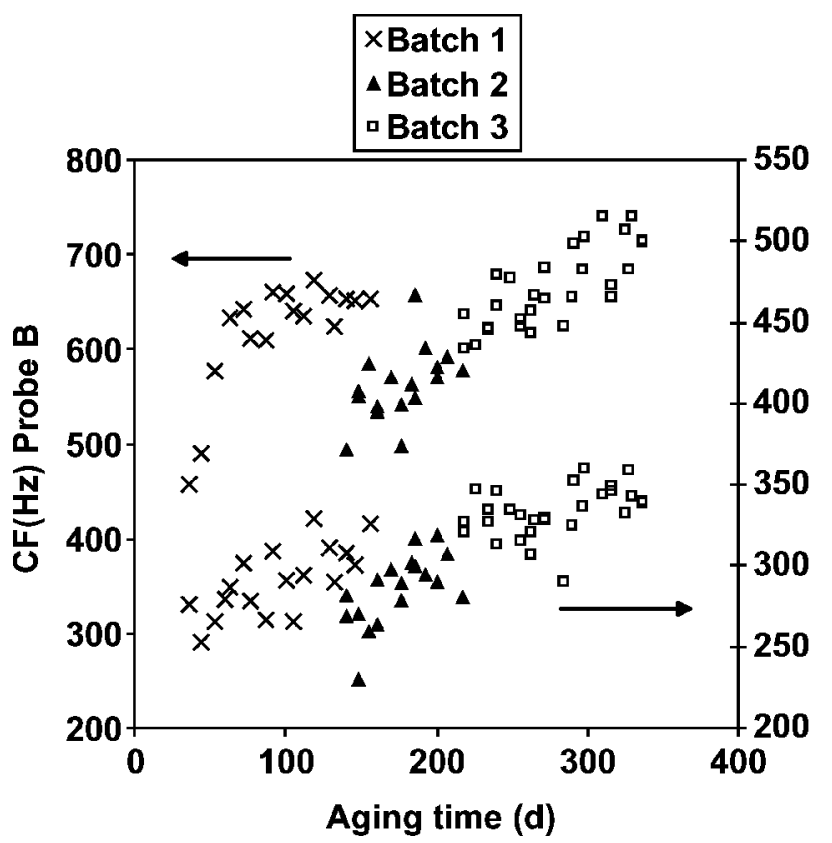

Figure 5. Change of the acoustic characteristics of Manchego cheese during ripening. $\mathrm{CF}=$ central frequency. Maturity of pieces: batch $1=36$ to $156 \mathrm{~d}$; batch $2=140$ to $218 \mathrm{~d}$; and batch $3=219$ to $336 \mathrm{~d}$.

For probe B, the best correlation coefficients are for the relationships between the $\mathrm{CF}$ and the MF for the spherical and semispherical probes $(\mathrm{r}=0.851$ and 0.861 , respectively). Moreover, good relationships are found for external textural measurements calculated for low sample deformation such as the slopes $(\mathrm{r}=0.851$ and 0.842 for the spherical and semispherical probes, respectively). Lower but also satisfactory correlations are

Table 3. Linear correlation coefficients between acoustic parameters and maturing time $\mathrm{e}^{1,2}$

\begin{tabular}{llll}
\hline & Probe A & & Probe B \\
\hline $\mathrm{M}_{0}\left(\mathrm{~V} \mathrm{~Hz}^{1 / 2}\right)$ & 0.811 & $\left.\mathrm{Mo}^{1 / 2 ~ H z} \mathrm{~V} \mathrm{H}^{1 / 2}\right)$ & 0.495 \\
$\mathrm{M}_{1}\left(\mathrm{~V} \mathrm{~Hz}^{3 / 2}\right)$ & 0.828 & $\mathrm{M}_{1}\left(\mathrm{~V} \mathrm{~Hz}^{3 / 2}\right)$ & 0.645 \\
$\mathrm{CF}(\mathrm{Hz})$ & 0.759 & $\mathrm{CF}(\mathrm{Hz})$ & 0.584 \\
$\mathrm{Var}(\mathrm{Hz})$ & 0.749 & $\mathrm{Var}(\mathrm{Hz})$ & $0.020^{* *}$ \\
$\mathrm{M}_{01}\left(\mathrm{~V} \mathrm{~Hz}^{1 / 2}\right)$ & $0.261^{*}$ & $\mathrm{M}_{01}\left(\mathrm{~V} \mathrm{~Hz}^{1 / 2}\right)$ & 0.352 \\
$\mathrm{M}_{02}\left(\mathrm{~V} \mathrm{~Hz}^{1 / 2}\right)$ & 0.708 & $\mathrm{M}_{02}\left(\mathrm{~V} \mathrm{~Hz}^{1 / 2}\right)$ & 0.614 \\
$\mathrm{M}_{03}(\mathrm{~V} \mathrm{~Hz})$ & 0.817 & $\mathrm{M}_{11}\left(\mathrm{~V} \mathrm{~Hz}^{3 / 2}\right)$ & 0.524 \\
$\mathrm{CF}_{1}(\mathrm{~Hz})$ & 0.672 & $\mathrm{M}_{12}\left(\mathrm{~V} \mathrm{~Hz}^{3 / 2}\right)$ & 0.608 \\
$\mathrm{CF}_{2}(\mathrm{~Hz})$ & 0.308 & $\mathrm{CF}_{1}(\mathrm{~Hz})$ & 0.762 \\
$\mathrm{CF}_{3}(\mathrm{~Hz})$ & 0.777 & $\mathrm{CF}_{2}(\mathrm{~Hz})$ & $0.048^{* *}$ \\
\hline
\end{tabular}

${ }^{1}$ Values with no asterisk indicate that the relationships are statistically significant $(P<0.01)$.

${ }^{2} \mathrm{M}_{0}, \mathrm{M}_{1}=$ Moments of order 0 and 1 of the frequency spectrum; $\mathrm{CF}=$ central frequency of the entire spectrum; Var = variance of the frequency spectrum; $\mathrm{M}_{01}, \mathrm{M}_{02}, \mathrm{M}_{03}=$ moments of order 0 in sections 1,2 , and 3 of the frequency spectrum; $\mathrm{CF}_{1}, \mathrm{CF}_{2}, \mathrm{CF}_{3}=$ central frequencies of sections 1,2 , and 3 .

$* P>0.01 ; * * P>0.05$.
Table 4. Loading matrix for the principal component (PC) analysis of the acoustic variables

\begin{tabular}{|c|c|c|c|c|}
\hline & $\begin{array}{l}\text { PC1 } \\
(47.6 \%)^{1}\end{array}$ & $\begin{array}{l}\text { PC2 } \\
(22.7 \%)^{1}\end{array}$ & $\begin{array}{l}\text { PC3 } \\
(10.9 \%)^{1}\end{array}$ & $\begin{array}{l}\mathrm{PC} 4 \\
(7.4 \%)^{1}\end{array}$ \\
\hline \multicolumn{5}{|l|}{ Probe $A^{2}$} \\
\hline $\mathrm{M}_{1}\left(\mathrm{~V} \mathrm{~Hz}^{3 / 2}\right)$ & 0.792 & -0.088 & -0.202 & -0.003 \\
\hline $\mathrm{CF}(\mathrm{Hz})$ & 0.924 & -0.196 & -0.143 & 0.100 \\
\hline $\operatorname{Var}(\mathrm{Hz})$ & 0.809 & 0.061 & -0.374 & 0.269 \\
\hline $\mathrm{M}_{01}\left(\mathrm{~V} \mathrm{~Hz}^{1 / 2}\right)$ & 0.096 & 0.665 & -0.568 & -0.278 \\
\hline $\mathrm{M}_{02}\left(\mathrm{~V} \mathrm{~Hz}^{1 / 2}\right)$ & 0.721 & -0.089 & -0.338 & -0.469 \\
\hline $\mathrm{M}_{03}\left(\mathrm{~V} \mathrm{~Hz}^{1 / 2}\right)$ & 0.894 & -0.031 & -0.320 & -0.259 \\
\hline $\mathrm{CF}_{1}(\mathrm{~Hz})$ & 0.760 & -0.042 & -0.313 & 0.231 \\
\hline $\mathrm{CF}_{2}(\mathrm{~Hz})$ & 0.324 & 0.423 & 0.008 & 0.764 \\
\hline $\mathrm{CF}_{3}(\mathrm{~Hz})$ & 0.888 & -0.051 & -0.285 & 0.172 \\
\hline \multicolumn{5}{|l|}{ Probe $\mathrm{B}^{3}$} \\
\hline $\mathrm{CF}(\mathrm{Hz})$ & 0.787 & -0.434 & 0.383 & 0.061 \\
\hline $\operatorname{Var}(\mathrm{Hz})$ & 0.225 & -0.914 & 0.082 & 0.014 \\
\hline $\mathrm{M}_{01}\left(\mathrm{~V} \mathrm{~Hz}^{1 / 2}\right)$ & 0.305 & 0.883 & 0.189 & -0.164 \\
\hline $\mathrm{M}_{02}\left(\mathrm{~V} \mathrm{~Hz}^{1 / 2}\right)$ & 0.824 & 0.038 & 0.521 & -0.151 \\
\hline $\mathrm{M}_{11}\left(\mathrm{~V} \mathrm{~Hz}^{3 / 2}\right)$ & 0.518 & 0.774 & 0.279 & -0.128 \\
\hline $\mathrm{M}_{12}\left(\mathrm{~V} \mathrm{~Hz}^{3 / 2}\right)$ & 0.828 & -0.049 & 0.507 & -0.157 \\
\hline $\mathrm{CF}_{1}(\mathrm{~Hz})$ & 0.854 & 0.237 & 0.384 & 0.052 \\
\hline $\mathrm{CF}_{2}(\mathrm{~Hz})$ & 0.190 & -0.842 & -0.055 & -0.136 \\
\hline
\end{tabular}

${ }^{1}$ Percentage of explained variance by each PC; values in bold indicate the variables that are highly correlated to each PC.

${ }^{2} \mathrm{M}_{1}=$ Moment of order 1 of the frequency spectrum; $\mathrm{CF}=$ central frequency of the entire spectrum; Var = variance of the frequency spectrum; $\mathrm{M}_{01}, \mathrm{M}_{02}, \mathrm{M}_{03}=$ moments of order 0 in sections 1 , 2, and 3 of the frequency spectrum; $\mathrm{CF}_{1}, \mathrm{CF}_{2}, \mathrm{CF}_{3}=$ central frequencies of sections 1,2 , and 3 .

${ }^{3} \mathrm{M}_{11}, \mathrm{M}_{12}=$ Moments of order 1 in sections 1 and 2 of the frequency spectrum.

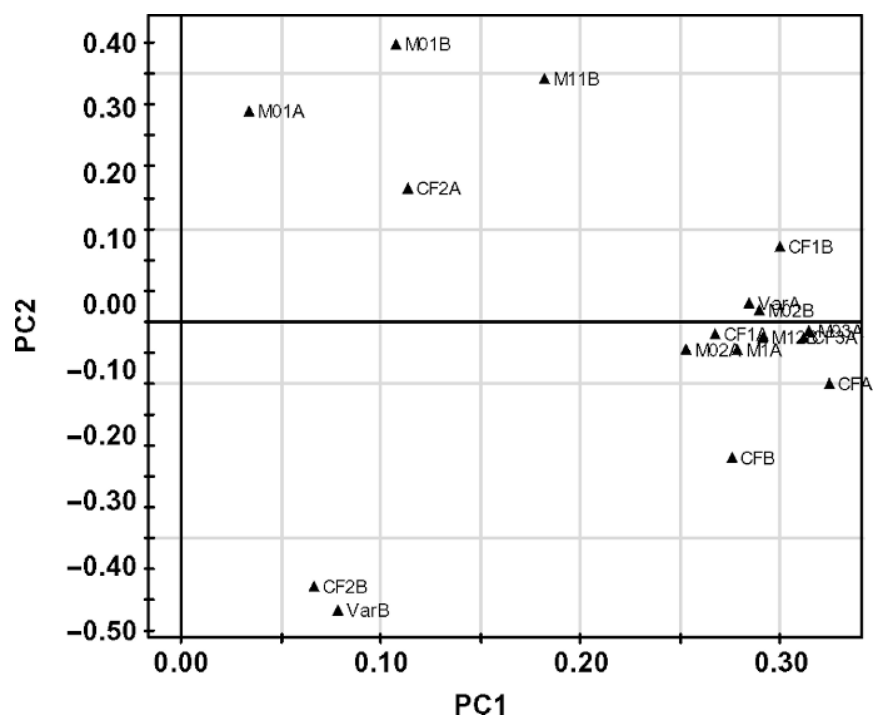

Figure 6. Principal component (PC) analysis loading plot of the acoustic parameters of Manchego cheese (subscript A denoting probe $\mathrm{A}$ and $\mathrm{B}$ probe $\mathrm{B}$ ). $\mathrm{M}_{1}=$ Moment of order 1 of the frequency spectrum; $\mathrm{CF}=$ central frequency of the entire spectrum; $\mathrm{Var}=$ variance of the frequency spectrum; $\mathrm{M}_{01}, \mathrm{M}_{02}, \mathrm{M}_{03}=$ moments of order 0 in sections 1,2 , and 3 of the frequency spectrum; $\mathrm{CF}_{1}, \mathrm{CF}_{2}, \mathrm{CF}_{3}=$ central frequencies of sections 1,2 , and $3 ; \mathrm{M}_{11}, \mathrm{M}_{12}=$ moments of order 1 in sections 1 and 2 of the frequency spectrum. 
Table 5. Correlation coefficients between the acoustical parameters and cheese texture and moisture ${ }^{1,2}$

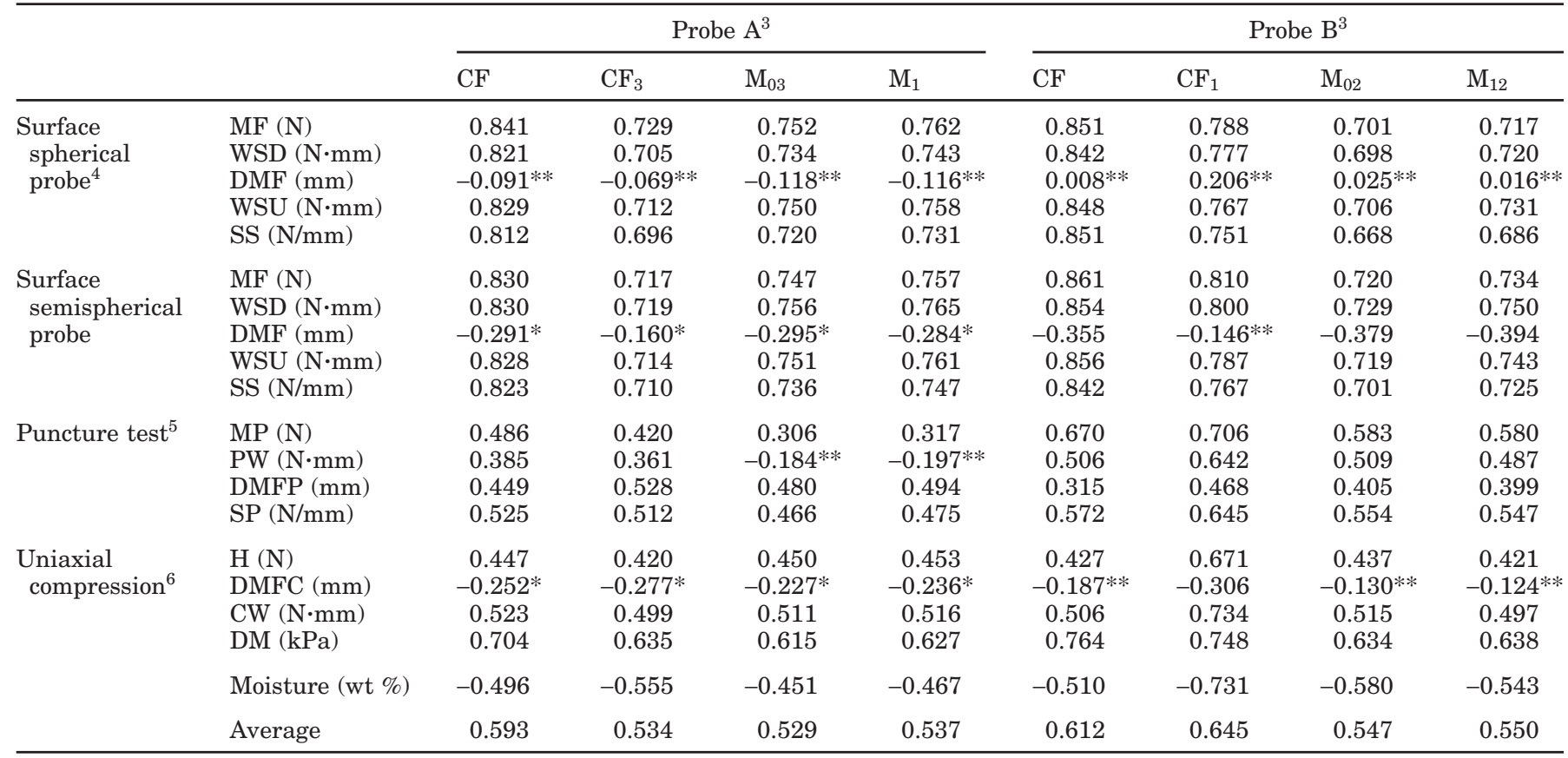

${ }^{1}$ Due to the large number of variables and in order reduce the table's data size, only the acoustical parameters accounting with $\mathrm{r}>0.7$ (for any of the relationships with the textural parameters) have been included.

${ }^{2}$ Values with no asterisk indicate that the relationships are statistically significant $(P<0.01)$.

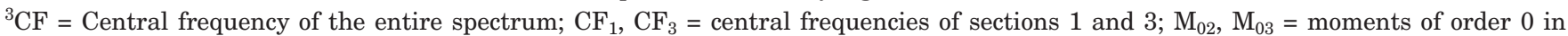
sections 2 and 3 of the frequency spectrum; $M_{1}=$ moment of order 1 of the frequency spectrum; $M_{12}=$ moment of order 1 in section 2 of the frequency spectrum.

${ }^{4} \mathrm{MF}=$ Maximum force; WSD = downstroke compression work; DMF = distance to maximum force; WSU = upstroke work; SS = initial compression slope.

${ }^{5} \mathrm{MP}=$ Maximum in puncture; $\mathrm{PW}=$ puncture work; DMFP = distance to maximum force to puncture; $\mathrm{SP}=$ slope in puncture.

${ }^{6} \mathrm{H}=$ Hardness; DMFC = distance to maximum force to compress; $\mathrm{CW}=$ compression work; $\mathrm{DM}=$ deformability modulus.

$* P>0.01 ; * * P>0.05$

found for the $\mathrm{CF}_{1}$, which shows that the main changes in the spectra, related to changes in texture, take place in the range of frequencies from 93 to $815 \mathrm{~Hz}$. By contrast, the coefficients for predicting internal parameters from acoustical measurements are much lower than those for the external ones. The best predictor of the internal texture is the $\mathrm{CF}_{1}$. The highest values correspond to the relationships between the $\mathrm{CF}$ and $\mathrm{CF}_{1}$ and $\mathrm{DM}(\mathrm{r}=0.764$ and 0.748 , respectively).

Therefore, it seems that most of the information collected from the acoustic impulse-response technique arrives from the external layers of the cheese pieces. As a consequence, the more closely related the internal and surface characteristics, the better the prediction of the internal texture from acoustical nondestructive measurements. Furthermore, the spectrum frequency distribution for both types of tests (probes A and B) seems to be the best predictor of the external and internal textural characteristics due to the changes in the vibration behavior of the pieces during ripening. The slightly better correlation coefficients for probe B can be attributed either to the distinct vibration modes that provide different information (note the different frequency range shown in Figures $4 a$ and b) or to operator variability because the experiments with probe A were done by hand.

Given the difficulty in obtaining information from the cheese pieces by finger-pressing hard samples, expert cheese-makers have traditionally hit the pieces by hand or with a hammer and listened to the sound emitted, extracting information regarding maturity or internal cracking. Giangiacomo et al. (1989) reported a change in the number and position of peaks in the spectrum when Grana cheeses had internal cracks.

When the acoustic impulse-response technique was used to evaluate firmness in tomatoes, a logarithmic relationship was identified between stiffness measurements and firmness measured by a panel of experts (Schotte et al., 1999). The firmness of pears was also evaluated from the change of the stiffness coefficient (De Belie et al., 2000b). The correlation coefficients between stiffness and the maximum force of compression 
Table 6. Multiple linear regression models for predicting textural parameters from acoustical tests

\begin{tabular}{|c|c|c|c|c|}
\hline & & $\mathrm{R}^{2}$ & Probe $A^{1}$ & Probe $\mathrm{B}^{1}$ \\
\hline Surface spherical probe ${ }^{2}$ & $\begin{array}{l}\text { MF }(\mathrm{N}) \\
\text { WSD }(\mathrm{N} \cdot \mathrm{mm}) \\
\text { DMF }(\mathrm{mm}) \\
\text { WSU }(\mathrm{N} \cdot \mathrm{mm}) \\
\text { SS }(\mathrm{N} / \mathrm{mm})\end{array}$ & $\begin{array}{l}0.937 \\
0.922 \\
0.380 \\
0.918 \\
0.924\end{array}$ & $\begin{array}{l}\mathrm{CF}, \mathrm{CF}_{3}, \mathrm{M}_{01} \\
\mathrm{CF}, \mathrm{CF}_{3}, \mathrm{M}_{02} \\
\mathrm{CF} \\
\mathrm{CF}, \mathrm{CF}_{3}, \mathrm{M}_{01} \\
\mathrm{CF}, \mathrm{CF}_{3}, \mathrm{M}_{01}\end{array}$ & $\begin{array}{l}\mathrm{CF}_{1}, \mathrm{CF}_{2}, \mathrm{CF}, \mathrm{M}_{11}, \mathrm{M}_{12} \text {, Var } \\
\mathrm{CF}_{1}, \mathrm{CF}_{2}, \mathrm{CF}, \mathrm{M}_{11}, \mathrm{M}_{12}, \text { Var } \\
\mathrm{M}_{11}, \mathrm{M}_{12}, \mathrm{M}_{01}, \text { Var } \\
\mathrm{CF}_{1}, \mathrm{CF}, \mathrm{M}_{11}, \mathrm{M}_{12} \\
\mathrm{CF}_{1}, \mathrm{CF}_{2}, \mathrm{CF}, \mathrm{M}_{12}, \mathrm{M}_{01} \text {, Var }\end{array}$ \\
\hline Surface semispherical probe & $\begin{array}{l}\text { MF }(\mathrm{N}) \\
\text { WSD }(\mathrm{N} \cdot \mathrm{mm}) \\
\text { DMF }(\mathrm{mm}) \\
\text { WSU }(\mathrm{N} \cdot \mathrm{mm}) \\
\text { SS }(\mathrm{N} / \mathrm{mm})\end{array}$ & $\begin{array}{l}0.937 \\
0.930 \\
0.538 \\
0.925 \\
0.903\end{array}$ & $\begin{array}{l}\mathrm{CF}_{2}, \mathrm{CF}, \mathrm{CF}_{3}, \mathrm{M}_{1} \\
\mathrm{CF}_{2}, \mathrm{CF}, \mathrm{CF}_{3}, \mathrm{M}_{1} \\
\mathrm{CF}, \mathrm{Var} \\
\mathrm{CF}, \mathrm{CF}_{3}, \mathrm{M}_{1} \\
\mathrm{CF}, \mathrm{CF}_{3}, \mathrm{M}_{1}\end{array}$ & $\begin{array}{l}\mathrm{CF}_{1}, \mathrm{CF}, \mathrm{M}_{11}, \mathrm{M}_{12}, \text { Var } \\
\mathrm{CF}_{1}, \mathrm{CF}, \mathrm{M}_{11}, \mathrm{M}_{02}, \text { Var } \\
\mathrm{CF}_{1}, \mathrm{CF}, \mathrm{M}_{11}, \mathrm{M}_{12}, \mathrm{M}_{01} \\
\mathrm{CF}_{1}, \mathrm{CF}, \mathrm{M}_{11}, \mathrm{M}_{02}, \text { Var } \\
\mathrm{CF}_{1}, \mathrm{CF}_{2}, \mathrm{CF}, \mathrm{M}_{12}, \mathrm{M}_{01}, \text { Var }\end{array}$ \\
\hline Puncture test ${ }^{3}$ & $\begin{array}{l}\mathrm{MP}(\mathrm{N}) \\
\mathrm{PW}(\mathrm{N} \cdot \mathrm{mm}) \\
\mathrm{DMFP}(\mathrm{mm}) \\
\mathrm{SP}(\mathrm{N} / \mathrm{mm})\end{array}$ & $\begin{array}{l}0.624 \\
0.525 \\
0.372 \\
0.479\end{array}$ & $\begin{array}{l}\mathrm{M}_{1} \\
\mathrm{M}_{1} \\
\mathrm{M}_{01}\end{array}$ & $\begin{array}{l}\mathrm{CF}_{1}, \text { Var } \\
\mathrm{CF}_{1} \\
\mathrm{CF} \\
\mathrm{CF}_{1}, \mathrm{M}_{11}, \mathrm{M}_{01}\end{array}$ \\
\hline \multirow[t]{2}{*}{ Uniaxial compression ${ }^{4}$} & $\begin{array}{l}\mathrm{H}(\mathrm{N}) \\
\mathrm{DMFC}(\mathrm{mm}) \\
\mathrm{CW}(\mathrm{N} \cdot \mathrm{mm}) \\
\mathrm{DM}(\mathrm{kPa})\end{array}$ & $\begin{array}{l}0.586 \\
0.635 \\
0.602 \\
0.719\end{array}$ & $\begin{array}{l}\mathrm{CF}_{2} \\
\mathrm{M}_{03} \\
\mathrm{M}_{03}\end{array}$ & $\begin{array}{l}\mathrm{CF}_{1}, \mathrm{M}_{02} \\
\mathrm{CF}_{1}, \mathrm{M}_{11}, \mathrm{M}_{01} \\
\mathrm{CF}_{1}, \mathrm{M}_{02} \\
\mathrm{CF}_{1}, \mathrm{M}_{11}\end{array}$ \\
\hline & $\begin{array}{l}\text { Moisture (wt\%) } \\
\text { Aging time (d) }\end{array}$ & $\begin{array}{l}0.730 \\
0.844\end{array}$ & $\begin{array}{l}\mathrm{CF}_{3}, \mathrm{M}_{02}, \mathrm{M}_{1} \\
\mathrm{CF}_{1} \mathrm{CF}, \mathrm{CF}_{3}, \mathrm{M}_{03}\end{array}$ & $\begin{array}{l}\mathrm{CF}_{1}, \mathrm{CF}_{2}, \mathrm{M}_{12}, \mathrm{M}_{02} \\
\mathrm{CF}_{1}\end{array}$ \\
\hline
\end{tabular}

${ }^{1} \mathrm{CF}=$ Central frequency of the entire spectrum; $\mathrm{CF}_{1}, \mathrm{CF}_{2}, \mathrm{CF}_{3}=$ central frequencies of sections 1,2 , and $3 ; \mathrm{M}_{0}, \mathrm{M}_{1}=$ moments of order 0 and 1 of the frequency spectrum; $\mathrm{M}_{01}, \mathrm{M}_{02}=$ moments of order 0 in sections 1 and 2 of the frequency spectrum; $\mathrm{M}_{11}, \mathrm{M}_{12}=$ moments of order 1 in sections 1 and 2 of the frequency spectrum; Var = variance of the frequency spectrum.

${ }^{2} \mathrm{MF}=$ Maximum force; WSD = downstroke compression work; DMF = distance to maximum force; WSU = upstroke work; SS = initial compression slope.

${ }^{3} \mathrm{MP}=$ Maximum in puncture; $\mathrm{PW}=$ puncture work; $\mathrm{DMFP}=$ distance maximum force to puncture; $\mathrm{SP}=$ slope in puncture.

${ }^{4} \mathrm{H}=$ Hardness $; \mathrm{DMFC}=$ distance to maximum force to compress; $\mathrm{CW}=$ compression work; $\mathrm{DM}$ = deformability modulus.

and the modulus of elasticity were 0.59 and 0.64 , respectively for Conference pears and 0.82 and 0.6 , respectively, for Doynné pears. Similar positive correlation coefficients between destructive textural measurements and resonant frequency were reported for apples ( $\mathrm{Lu}$ and Abbott, 1996).

As mentioned earlier, texture is a multidimensional sensory quality attribute that requires a variety of instrumental parameters to be properly described. In this respect, a single acoustic parameter may not be able to accurately characterize instrumental parameters; consequently, multivariate techniques might be useful for a better textural characterization.

\section{Multivariate Analysis for Predicting Cheese Texture}

To estimate the textural characteristics of cheese, multivariate regression combines the information provided by tests performed on the lateral and upper surfaces of the cheese pieces. A stepwise multiple regression was carried out including all the acoustic variables. Table 6 shows the percentage of explained variance as well as the variables included in the model after the optimization algorithm. As with the single regressions, the best predicted surface parameters are the MF for the spherical and semispherical probes $\left(R^{2}=0.939\right.$ and 0.937, respectively). Except for those corresponding to the DMF, all the other correlations were higher than 0.910. In all the models, the CF that showed to be the best related to textural changes has been included. Also $\mathrm{CF}_{1}$ for probe $\mathrm{B}$ and $\mathrm{CF}_{3}$ for probe $\mathrm{A}$ appeared in all the regression models. Once more, the internal parameters are the worst predicted $\left(R^{2}<0.640\right)$ except for the DM $\left(\mathrm{R}^{2}=0.719\right)$. Moisture $\left(\mathrm{R}^{2}=0.730\right)$ and ripening time $\left(R^{2}=0.844\right)$ can also be assessed, although with lower percentages of explained variance than for external texture.

The PLSR was applied on the 64 samples including all the variables (texture, moisture, and acoustic parameters) in the model. The advantage of this method over MLR is that a cross-validation technique is used, and the prediction ability is calculated and used to determine the optimum number of components in the model. Poveda et al. (2004) also used PLSR to predict the ripening time of Manchego cheese from $\mathrm{pH}$, water activity, and DM.

Three components were found to account for $79 \%$ of the explained variance. Table 7 shows the percentage 
Table 7. Partial least square regression models for predicting textural parameters from acoustical tests

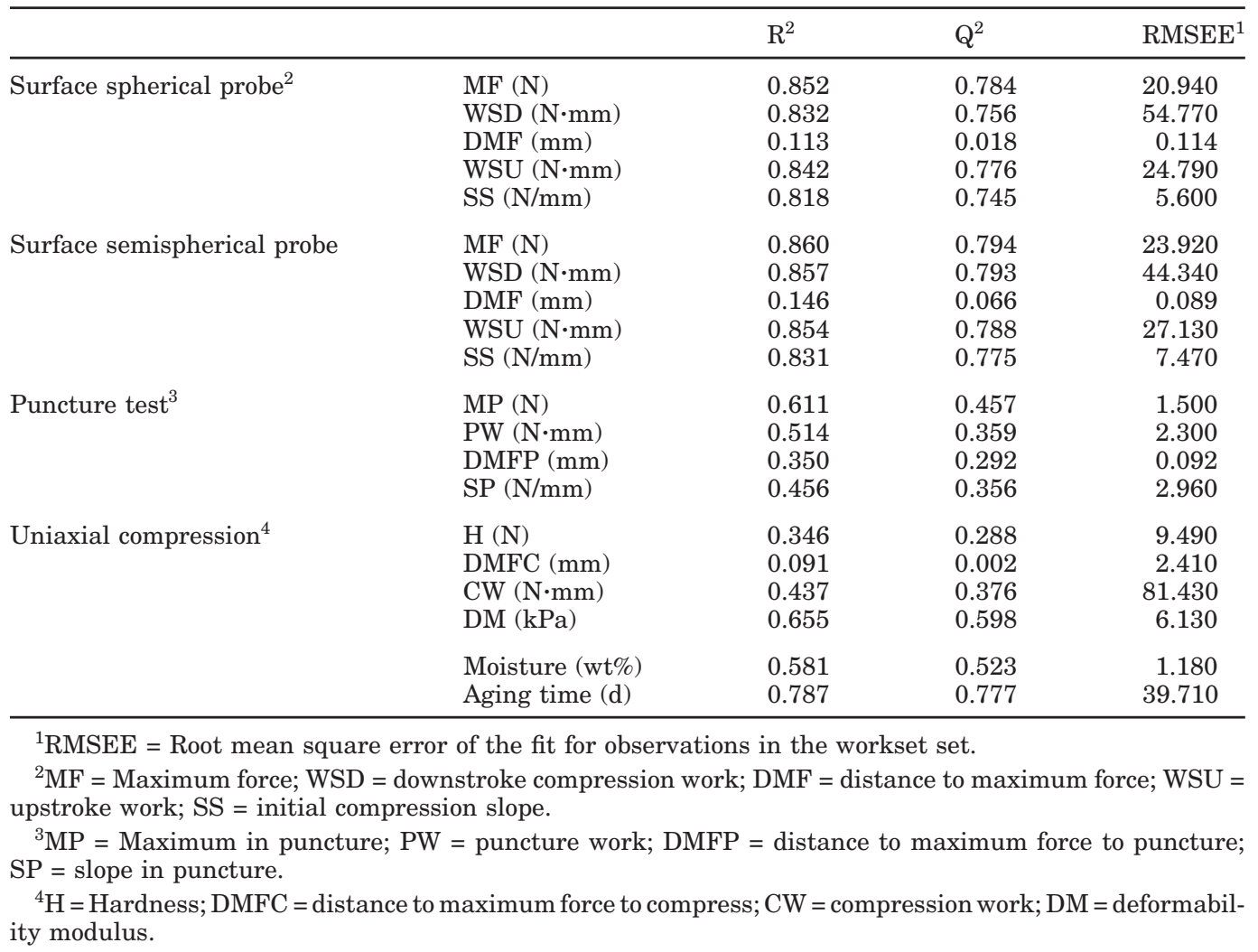

of explained variance, the prediction ability, as well as the root mean square error of the fit for observations in the workset set (RMSEE) obtained by cross-validation. The results agree with those found with MLR. The external textures were well predicted (maximum values for MF, spherical, and semispherical probes), but the distances at the maximum force and lower percentages of explained variance were observed for the internal texture. The variable influence on projection showed that the $\mathrm{CF}$ and $\mathrm{M}_{1}$ were the most relevant parameters in the model for probe $\mathrm{A}$, whereas $\mathrm{CF}$ and $\mathrm{CF}_{1}$ were for probe $\mathrm{B}$, which shows the importance of the central frequency in the models.

Thus, the acoustic impulse-response technique along with the use of multivariate analysis may be a good method for predicting textural characteristics of Manchego cheese during ripening. The external textural characteristics of the cheese pieces were better predicted than were the internal ones. Increasing the force of the impact might allow the vibration to penetrate deeper into the cheese mass, and provide more information about the internal layers.

\section{CONCLUSIONS}

Manchego cheese showed an increase in the internal and surface textural parameters during ripening while losing water content. An acoustic technique was assayed to evaluate the textural properties of Manchego cheese by recording the sound emitted by the cheese after being hit. The frequency distribution of the spectra allowed for the study of changes in texture during ripening. This technique provided better information about the external textural changes than the internal ones. The MLR and PLSR proved to be effective tools for constructing accurate models that not only integrate all the information extracted from the acoustic spectrum but also predict the textural properties and degree of maturity. The technique is fast and inexpensive and could be used online in the production chain. Further research should explore both the influence of the mass and shape of the cheese pieces on the acoustic measurements and the use of this technique to detect internal cracks.

\section{ACKNOWLEDGMENTS}

Financial support for this research has been provided by the Spanish Ministerio de Ciencia y Tecnología, INIA (CAL01-077-C3-1).

\section{REFERENCES}

AOAC. 1984. Official Methods of Analysis. 14th ed. Association of Official Analytical Chemists, Washington, DC. 
Benedito, J., J. A. Cárcel, G. Clemente, and A. Mulet. 2000a. Cheese maturity assessment using ultrasonics. J. Dairy Sci. 83:248-254.

Benedito, J., J. A. Cárcel, N. Sanjuan, and A. Mulet. 2000b. Use of ultrasound to assess Cheddar cheese characteristics. Ultrasonics 38:727-730.

Benedito, J., R. González, C. Rosselló, and A. Mulet. 2000c. Instrumental and expert assessment of Mahón cheese texture. J. Food Sci. 65:1170-1174.

Benedito, J., A. Mulet, G. Clemente, and J. V. García-Pérez. 2004 Use of ultrasonics for the composition assessment of olive mill wastewater (alpechin). Food Res. Intern. 37:595-601.

Benedito, J., S. Simal, G. Clemente, and A. Mulet. 2006. Manchego cheese texture evaluation by ultrasonics and surface probes. Int. Dairy J. 16:431-438.

Breuil, P., and J. F. Meullenet. 2001. A comparison of three instrumental tests for predicting sensory texture profiles of cheese. J. Texture Stud. 32:41-55.

Cho, H. K., W. K. Choi, and J. H. Paek. 2000. Detection of surface cracks in shell eggs by acoustic impulse method. Trans. ASAE 43:1921-1926.

De Belie, N., S. Schotte, P. Coucke, and J. De Baerdemaeker. 2000a. Development of an automated monitoring device to quantify changes in firmness of apples during storage. Postharvest Biol. Technol. 18:1-8.

De Belie, N., S. Schotte, J. Lammertyn, B. Nicolai, and J. De Baerdemaeker. 2000b. Firmness changes of pear fruit before and after harvest with the acoustic impulse response technique. J. Agric. Eng. Res. 77:183-191.

De Ketelaere, B., P. Coucke, and J. De Baerdemaeker. 2000. Eggshell crack detection based on acoustic resonance frequency analysis. J. Agric. Eng. Res. 76:157-163.

Duizer, L. M., and O. H. Campanella. 1998. Sensory, instrumenta and acoustic characteristics of extruded snack food products. J. Texture Stud. 29:397-411.
Giangiacomo, R., G. Messina, and F. Abbiati. 1989. Confronto tra la risonanza acustica strumentale e la battitura per la valutazione commerciale di formaggio Grana. Latte 14:126-129.

Imran, A. H., J. Sugiyama, A. Tomizawa, and Y. Sagara. 2004. Nondestructive acoustic firmness tester detects the effect of manure on muskmelon texture. HortScience 39:142-145.

Kulmyrzaev, A., E. Dufour, Y. Noël, M. Hanafi, R. Karoui, E. M. Qannari, and G. Mazerolles. 2005. Investigation at the molecular level of soft cheese quality and ripening by infrared and fluorescence spectroscopies and chemometrics - relationships with rheology properties. Int. Dairy J. 15:669-678.

Lu, R., and J. A. Abbott. 1996. Finite element analysis of modes of vibration in apples. J. Texture Stud. 27:265-286.

McClements, D. J. 1997. Ultrasonic characterization of food and drinks: Principles, methods and applications. Crit. Rev. Food Sci. Nutr. 37:1-46.

Mulet, A., J. Benedito, Y. Golas, and J. A. Cárcel. 2002. Noninvasive ultrasonic measurements in the Food Industry. Food Rev. Int. 18:123-133.

Muramatsu, N., N. Sakurai, R. Yamamoto, and D. Nevis. 1996. Nondestructive acoustic measurements of firmness for nectarines, apricots, plums and tomatoes. HortScience 31:1199-1202.

Poveda, J. M., A. García, P. J. Marín-Álvarez, and L. Cabezas. 2004. Application of partial least squares (PLS) regression to predict the ripening time of Manchego cheese. Food Chem. 84:29-33.

Schmulevich, I., N. Galili, and D. Rosenfeld. 1996. Detection of fruit firmness by frequency analysis. Trans. ASAE 39:1047-1055.

Schotte, S., N. De Belie, and J. De Baerdemaeker. 1999. Acoustic impulse-response technique for evaluation and modeling of firmness of tomato fruit. Postharvest Biol. Technol. 17:105-115.

Toyoshima, T., K. Tsuchiya, F. Satoh, and H. Tachibana. 2004. Objective evaluation of the texture of deep-fried foods by sound analysis and mastication pressure. J. Jpn. Soc. Food Sci. Technol. $51: 388-394$ 